\title{
Does the Interest Rate Form Business Cycle?
}

\author{
Bijan Bidabad \\ B.A., M.Sc., Ph.D., Post Doc. \\ Professor of Economics and Chief Islamic Banking Advisor \\ Bank Melli Iran, Tehran, Iran \\ Email: bijan@bidabad.com \\ Abul Hassan \\ Lecturer and Senior Research Fellow \\ Markfield Institute of Higher Education \\ University of Gloucestershire \\ Ratby Lane, Markfield, Leicestershire LE67 SY, UK. \\ Email: abul.hassan@mihe.org.uk
}

\begin{abstract}
Dynamic structural behavior of depositor, bank and borrower and the role of banks in forming business cycle are investigated. We test the hypothesis that does banks behavior make oscillations in the economy through the interest rate. By dichotomizing banking activities into two markets of deposit and loan, we show that these two markets have non-synchronized structures, and this is why the money sector fluctuation starts. As a result, the fluctuation is transmitted to the real economy through saving and investment functions. Empirical results assert that in the USA, the banking system creates fluctuations in the money sector and real economy as well through short-term interest rates
\end{abstract}

Keywords: Business cycle, Interest rate, Banking Sector.

JEL: E32, E43, G01

\section{Introduction}

There are several studies on business cycles from different points of view. The essence of these studies was to find out a solution on how to reform monetary and banking structure and overcome the economic crisis. The purpose of this paper is to examine the relationship between interest rates and business cycle formation. In the area of the business cycle, Fisher's (1933) "Theory of Credit Cycles" is one of the interesting theories discusses elaborately the causes of business cycles. He argues that credit cycles are the main reasons for economic cycles. Minsky (1992) puts forward the financial instability hypothesis, and in the line of Fisher's theory, he further argues on credit bubbles and their burst effects on economic cycles. While discussing the "Austrian Business Cycle Theory", Block and Barnett (2007) state that banking structure is one of the factors to create a crisis. Some other researches have also touched different aspects of the relation between interest rate and business cycle (Beaudry and Guay, 1996; Blankenau et al.,2001; Ivanova et al.,(2000); but none of these studies look at the fluctuation of bank interest rates which is one of the causes of business cycle in the economy. Therefore, this study attempted to show the comovements between interest rates and output.

\section{The Dichotomization of Money Market}

This study highlights on money market by bifurcating bank's behavior into two markets, namely saving-deposit and investment-credit markets in line with the studies of Bidabad $(2004,2010)$. In one hand, the demand of bank for deposits is kept at one side, which intersects with the supply of deposits (saving) and fixes deposit interest rate. On the other hand, the bank creates another market by supplying credit funds that intersects demand for credit and creates the loan interest rate. In view of this, the bank stands between two markets of supply and demand for funds in the money market. 
In case the consumption increases, the supply of bank deposits will fall. As a result, there will be an increase in the deposit interest rate. The increase in deposit interest rate cannot instantly increase credit-lending interest rate because credit contracts have been fixed for a period, and the bank has to wait for contract maturity to increase the rate. Therefore, the bank will face loss during this period, and thereafter, it will be compensated by increasing the loan interest rate by a time lag. This lag, from an economic point of view, creates a special dynamic relationship between supply and demand for money. In the following lines, mathematically shown that because of this lag, the relationship between these two variables (supply and demand for money) is a second order difference equation. Second order difference equations have the ability to create the cycles. In other words, fluctuation of the real economy is induced by fluctuations in the money market. The most important effect of elimination of interest rate (Islamic banking) is to bridge between investment and saving. This analysis is shown in the following graph:

Saving interest rate

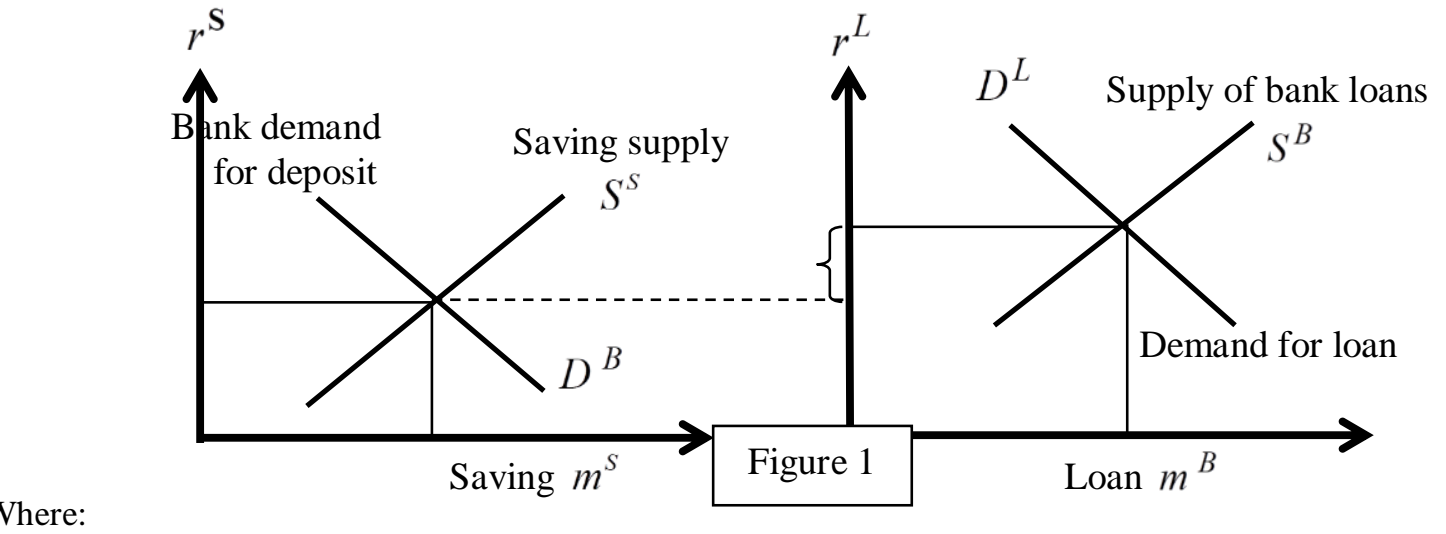

Where:

Bank's revenue at the time $t$ is equal to:

$$
R_{t}=m_{t}^{B} r_{t}^{L}-m_{t}^{S} r_{t}^{S}
$$

At equilibrium, we have:

$m_{t}^{B}=D_{t}^{L}=S_{t}^{B}$

$m_{t}^{S}=D_{t}^{B}=S_{t}^{S}$

In case the demand for loans decreases, $\mathrm{D}_{\mathrm{t}}^{\mathrm{L}}$ moves from the left side to $\mathrm{D}_{\mathrm{t}+1}{ }^{\mathrm{L}}$. In the new equilibrium, if the bank's revenue turns negative, we will get the following equations:

$r_{t+1}^{L}<r_{t}^{L}$

Or:

$$
R_{t+1}=m_{t+1}^{B} r_{t+1}^{L}-m_{t}^{S} r_{t}^{S}<\text { o }
$$

Therefore, in respect of the time-based loan contract, the bank has to compensate losses during the period $t+1$ from other sources until the next period when $\mathrm{D}^{\mathrm{B}}$ curve moves to the left-hand side. It is shown below:

$$
\begin{aligned}
& r_{t+2}^{S}>r_{t+1}^{L} \\
& R_{t+2}=m_{t+1}^{B} r_{t+1}^{L}-m_{t+2}^{S} r_{t+2}^{S}>0
\end{aligned}
$$

By generalizing this hypothesis, we clearly see that whenever shocks occur in deposit supply or demand for banks' loans, because of time-based contracts, these shocks will be transferred to the other market in the next period. These fluctuations will effect from one market to another market and finally extend to other markets in the real economy as well.

By considering the sign of three equations of (1), (5) and (7), we can clearly see that the behavior of variable $\mathrm{R}$ is alternative in different periods. The behavior of the above-mentioned two markets may be similar to the Cob-Web 
model, which creates different fluctuation according to the gradient of different parts of supply and demand schedules. The interest rates in the two markets are:

$r_{t}^{S}=r^{S}\left(m_{t}^{S}\right)$

$r_{t}^{L}=r^{L}\left(m_{t}^{B}\right) \quad$ According to the above assumptions, if we adjust the relationship of the two markets with one time-lag, we will have:

$$
m_{t+1}^{S}=f\left(m_{t}^{B}\right)
$$

By replacing (8) and (9) in (10), we have:

$$
r_{t}^{S}=r^{S}\left(f\left(m_{t-1}^{B}\right)\right)=r^{S}\left(f\left(r^{L^{-1}}\left(r_{t-1}^{L}\right)\right)\right)
$$

In other words, the interest rate in the deposit market is a function of the interest rate in the loan market in the previous period. The adjustment takes place when the return movement occurs in the next period which means that the interest rate of the loan market is itself a function of the interest rate of the deposit market in the previous period, or:

$$
m_{t+1}^{B}=g\left(m_{t}^{S}\right)
$$

By replacing (10) in (12), we will have:

$$
m_{t+1}^{B}=g\left(f\left(m_{t-1}^{B}\right)\right)
$$

This is a second-order difference equation which is characterized to fluctuate easily in time, (Baumol,1958; Baumol and Turvey,1951). This is also true in the case of interest rates. By replacing (12) in (10), we have:

$$
m_{t+1}^{S}=f\left(g\left(m_{t-1}^{S}\right)\right)
$$

This equation, similar to (13) may be considered completely oscillatory. By replacing (12) in (9), we will have:

(15)

$r_{t}^{L}=r^{L}\left(g\left(m_{t-1}^{S}\right)\right)=r^{L}\left(g\left(r^{S^{-1}}\left(r_{t-1}^{L}\right)\right)\right)$

Since equations (15) and (11) are function of $\mathrm{m}_{\mathrm{t}-1} \mathrm{~s}$ and $\mathrm{m}_{\mathrm{t}-1}{ }^{\mathrm{B}}$ these two variables may be considered completely oscillatory according to (14) and (13). Hence, both loans and deposits markets may fluctuate due to interest rates and the amount of deposits and loans fluctuations. Considering the equilibrium at the macro level and its relationship with interest rate fluctuations induced by the banking behavior, we can go through the following national accounting relationship equations:

$$
\begin{aligned}
& \text { gdp }=\text { con }+\mathrm{inv}+\mathrm{gov}+\mathrm{ex}-\mathrm{im} \\
& \text { gde }=\text { con }+\mathrm{sav}+\mathrm{tax}+\mathrm{tr} \\
& \text { gdp }=\text { gde }
\end{aligned}
$$

In which:

$\begin{array}{ll}\text { gdp }=\text { gde } & \text { Gross domestic product }=\text { Gross domestic expenditure } \\ \text { con } & \text { Consumption } \\ \text { inv } & \text { Investment } \\ \text { gov } & \text { Government expenditures } \\ \text { ex } & \text { Exports } \\ \text { im } & \text { Imports }\end{array}$




$\begin{array}{ll}\text { sav } & \text { Savings } \\ \operatorname{tax} & \text { Tax } \\ \operatorname{tr} & \text { Transfer payments to outside }\end{array}$

By solving equation (16), macroeconomic equilibrium condition will be as follow:

$($ inv-sav $)+($ gov-tax $)+($ ex-im-tr $)=0$

In order to make simplification, we will only consider the two variables of investment and saving as functions of interest rates of saving deposits and loans $\left(\mathrm{r}^{\mathrm{S}}\right.$ and $\left.\mathrm{r}^{\mathrm{L}}\right)$. The equilibrium condition in the economy at time $\mathrm{t}$ will be the following:

$$
\left(\operatorname{inv}_{t}\left(r_{t}^{L}\right)-\operatorname{sav}_{t}\left(r_{t}^{S}\right)\right)+\left(g o v_{t}-\operatorname{tax}_{t}\right)+\left(e x_{t}-i m_{t}-t_{t}\right)=0
$$

By replacing $r_{t}^{S}$ and $r_{t}^{L}$ from equations (15) and (11) in equilibrium condition, we will have:

$$
\left(\operatorname{inv}_{\mathrm{t}}\left(r^{L}\left(g\left(r^{S^{-1}}\left(r_{t-1}^{L}\right)\right)\right)\right)-\operatorname{sav}_{\mathrm{t}}\left(r^{S}\left(f\left(r^{L^{-1}}\left(r_{t-1}^{L}\right)\right)\right)\right)+\left(\operatorname{gov}_{\mathrm{t}}-\operatorname{tax}_{\mathrm{t}}\right)+\left(\mathrm{ex}_{\mathrm{t}}-\operatorname{im}_{\mathrm{t}}-\mathrm{tr}_{\mathrm{t}}\right)=0\right.
$$

In case the government has balanced fiscal policy $\left(\operatorname{gov}_{t}-\operatorname{tax} t\right)=0$ and trade $\left(\operatorname{ex}_{t}-\mathrm{im}_{t}-\operatorname{tr}_{t}\right)=0$, then the equilibrium (19) is again a second-order difference equation which can lead the economy into oscillation.

\section{Empirical Investigations}

As we have shown mathematically, the behavioral difference of the equation in interest rates of the deposit and loan sources, create fluctuations in the money and capital markets. This phenomenon can easily fluctuate the aggregate supply and demand in the real sector through investment demand and saving supply functions as shown emphatically. Bidabad (1990) argues that if the time behavior of $\mathrm{y}_{\mathrm{t}}$ obeys a second order difference equation, type of roots (being real or complex or double), their absolute values (being larger or smaller than one), are critical for the shape of fluctuations.

In order to show the oscillatory natures of the interest rates, we need to conduct an empirical test to see whether the equations (11) and (15) are true in nature or not. Using the sample of USA data ${ }^{1}$ for the period of 1948-2009, we test weather equations (11) and (15) are oscillatory or not. If it is true, then the oscillation will be transferred to equations (18) and (19) which are the macroeconomic equilibrium condition. Our empirical results show that the source of oscillation is emanated from interest rates to the real sector. Ten types of short, medium, and long terms interest rates have been selected. We fit a second order linear non-homogenous difference equation to all 10 selected interest rates.

Table 1 shows all estimated parameters are statistically significant and proves that a second-order linear difference equation exists for all 10 interest rates. All short-term interest rates' difference equations have complex characteristic roots, but the characteristic roots of difference equations of medium and long terms interest rates are all real. These results prove that the source of fluctuations in the real economy comes from short-term interest rates. On the other side, the medium and long-term interest rates have real characteristic roots, which one of the pair is close to one or less than one. As a result, we can come in the conclusion that the medium and long-term interest rates dampen oscillation.

Table 1. Estimation results and characteristic roots of ten estimated equations

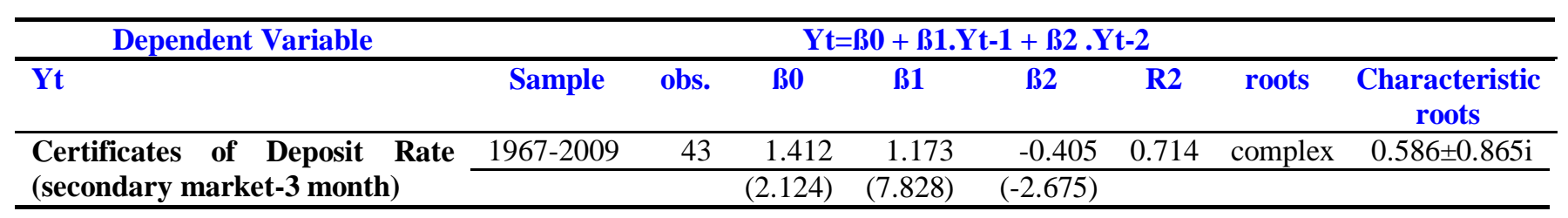

\footnotetext{
1 - International Monetary Fund, 2010. International Financial Statistics, 2010. Country Note, USA, http://www.imfstatistics.org
} 


\begin{tabular}{|c|c|c|c|c|c|c|c|c|}
\hline \multirow[t]{2}{*}{ Commercial Paper Rate } & 1974-2009 & 36 & 1.092 & 1.208 & -0.406 & 0.761 & complex & $0.603 \pm 0.877 \mathrm{i}$ \\
\hline & & & (1.609) & $(7.807)$ & $(-2.564)$ & & & \\
\hline \multirow[t]{2}{*}{ Discount Rate (End of Period) } & 1950-2009 & 60 & 0.877 & 1.168 & -0.349 & 0.774 & complex & $0.584 \pm 0.830 \mathrm{i}$ \\
\hline & & & $(2.387)$ & $(9.376)$ & $(-2.786)$ & & & \\
\hline \multirow[t]{2}{*}{ Federal Funds Rate } & $1957-2009$ & 53 & 1.159 & 1.121 & -0.332 & 0.721 & complex & $0.560 \pm 0.803 \mathrm{i}$ \\
\hline & & & $(2.241)$ & $(8.255)$ & $(-2.445)$ & & & \\
\hline \multirow[t]{2}{*}{ Lending Rate (Prime Rate) } & 1950-2009 & 60 & 1.193 & 1.195 & -0.364 & 0.799 & complex & $0.597 \pm 0.849 \mathrm{i}$ \\
\hline & & & $(2.553)$ & $(9.559)$ & $(-2.962)$ & & & \\
\hline \multirow{2}{*}{$\begin{array}{l}\text { Treasury Bill Rate(Bond } \\
\text { Equivalent-3 month ) }\end{array}$} & 1977-2009 & 33 & 0.920 & 1.212 & -0.384 & 0.768 & complex & $0.606 \pm 0.866 \mathrm{i}$ \\
\hline & & & $(1.412)$ & $(7.048)$ & $(-2.153)$ & & & \\
\hline \multirow[t]{2}{*}{ Mortgage Rate } & 1974-2009 & 36 & 0.713 & 1.301 & -0.386 & 0.874 & real & $0.843,0.458$ \\
\hline & & & $(1.140)$ & $(7.983)$ & $(-2.339)$ & & & \\
\hline \multirow[t]{2}{*}{ Treasury Bill Rate } & 1950-2009 & 60 & 0.738 & 1.173 & -0.330 & 0.792 & real & $0.705,0.469$ \\
\hline & & & $(2.126)$ & $(9.257)$ & $(-2.614)$ & & & \\
\hline \multirow{2}{*}{$\begin{array}{l}\text { Govt. Bond Yield: Long Term } \\
\text { (10 year) }\end{array}$} & 1956-2009 & 54 & 0.511 & 1.103 & -0.180 & 0.880 & real & $0.903,0.200$ \\
\hline & & & $(1.491)$ & $(7.973)$ & $(-1.319)$ & & & \\
\hline \multirow{2}{*}{$\begin{array}{l}\text { Govt. Bond Yield: } \text { Medium } \\
\text { Term (3 year) }\end{array}$} & 1950-2009 & 60 & 0.539 & 1.127 & -0.222 & 0.856 & real & $0.872,0.255$ \\
\hline & & & (1.656) & $(8.668)$ & $(-1.718)$ & & & \\
\hline
\end{tabular}

T-statistics are in parentheses.

\section{Conclusion}

This study shows that business cycles occur because of the dynamic structure of different interest rates. The results demonstrate that there is an inherent lag structure between deposit and loan interest rates. The observed lag structure actually forms a second-order difference equation behavior in the banking sector as a source of oscillations, which start from the money market and expands to the real economy. Using the sample of the United States interest rates data for the period of 1948-2009, the results show the short-term interest rates is one of the main causes of fluctuations. The estimated dynamic equations for short-term interest rates had complex characteristic roots that let the equations be oscillatory. The long-term and medium-term interest rates equations had real characteristic roots and were not oscillatory.

\section{References}

Baumol, W. J., Turvey, R; 1951. Economic Dynamics, Macmillan Press, New York.

Baumol, W. J; 1958. Topology of Second Order Linear Difference Equations with Constant Coefficients, Econometrica, 26: 258-287.

Beaudry, P; Guay, A; 1996. What Do Interest Rates Reveal About The Functioning of Real Business Cycle Models? Journal of Economic Dynamics and Control, 20, 1661-1682.

Bidabad, B; 1990. Difference Equations and the Stability of Equilibrium Dynamism, http://www.bidabad.com/doc/difference-equations.pdf

Bidabad, Bijan, Abul Hassan, Dynamic Lag Structure of Deposits and Loans Interest Rates and Business Cycles Formation. Journal of Financial Regulation and Compliance, Vol. 25 Issue: 2, pp.114-132, 2017. http://dx.doi.org/10.1108/JFRC-09-2016-0078

Bidabad, B; 2010. Stabilizing Business Cycles by PLS Banking and Ethic Economics, http://www.bidabad.com/doc/pls-business-cycles-en.pdf

Bidabad, B; 2010. Fluctuations and Business Cycles Prevention by New Financial Instruments and Banking Structure Reform. http://www.bidabad.com/doc/Fluctuations-and-Cycles.pdf

Bidabad, Bijan, Economic-juristic analysis of usury in consumption and investment loans and contemporary jurisprudence shortages in exploring legislator commandments. Proceeding of the 2nd International Islamic Banking Conference. The Monash University of Malaysia. 9-10 September 2004. Reprinted in: National Interest, Journal of the Center for Strategic Research, Vol. 2, No. 1, winter 2006, pp. 72-90. Tehran, Iran. Republished (revised) in: International Journal of Islamic Business \& Management, 3(2), 1-15, 2019. https://www.cribfb.com/journal/index.php/ijibm/article/view/275 http://www.bidabad.com/doc/reba-en.pdf http://www.bidabad.com/doc/reba-fa.pdf 
Bidabad, Bijan, Non-Usury Bank Corporation (NUBankCo), The Solution to Islamic banking, Proceeding of the 3rd International Islamic Banking and Finance Conference, The Monash University, KL, Malaysia, 16-17 November, 2005. International Journal of Shari'ah and Corporate Governance Research, 2(1), 53-66, 2019. https://www.cribfb.com/journal/index.php/ijscgr/article/view/276 http://www.bidabad.com/doc/NUBankCo-en.pdf

Blankenau, W., Kose, M.A; Yi, K. M; 2001. Can World Real Interest Rates Explain Business Cycles in A Small Open Economy? Journal of Economic Dynamics \& Control, 25, 867-889.

Block, W; Barnett II W; 2007. On Laidler Regarding The Austrian Business Cycle Theory. Review of Austrian Economics. Vol. 20 (1): 43-61.

Fisher, I; 1933. The Debt-Deflation Theory of Great Depressions, Econometrica, Vol. 1 (4),. 337-357 http://fraser.stlouisfed.org/docs/meltzer/fisdeb33.pdf

IMF (2010), International Financial Statistics 2010, Country Notes, USA; http://www.imfstatistics.org

Ivanova, D; Lahiri, K; Seitz, F; 2000. Interest Rate Spreads as Predictors of German Inflation and Business Cycles. International Journal of Forecasting 16: 39-58.

Minsky, H; 1992. The Financial Instability Hypothesis, Working Paper No 74, May 1992, pp. 6-8. http://www.levy.org/pubs/wp74.pdf

\section{Copyrights}

Copyright for this article is retained by the author(s), with first publication rights granted to the journal.

This is an open-access article distributed under the terms and conditions of the Creative Commons Attribution license (http://creativecommons.org/licenses/by/4.0/) 